\title{
ENVIRONMENTAL NOISE ASSESSMENT FOR SYNTHANE PILOT PLANT
}

\author{
By \\ Timothy Yen
}

Department of Industrial Environmental Health Sciences

Graduate School of Public Health

University of Pittsburgh

Pittsburgh, Pennsylvania 15261 


\section{DISCLAIMER}

This report was prepared as an account of work sponsored by an agency of the United States Government. Neither the United States Government nor any agency Thereof, nor any of their employees, makes any warranty, express or implied, or assumes any legal liability or responsibility for the accuracy, completeness, or usefulness of any information, apparatus, product, or process disclosed, or represents that its use would not infringe privately owned rights. Reference herein to any specific commercial product, process, or service by trade name, trademark, manufacturer, or otherwise does not necessarily constitute or imply its endorsement, recommendation, or favoring by the United States Government or any agency thereof. The views and opinions of authors expressed herein do not necessarily state or reflect those of the United States Government or any agency thereof. 


\section{DISCLAIMER}

Portions of this document may be illegible in electronic image products. Images are produced from the best available original document. 
ABSTRACT

Environmental noise data were obtained at eleven selected sites around the SYNTHANE Pilot Plant at Bruceton, Pennsylvania. The data revealed that noise emission from the plant has a significant impact upon an area as far as about a mile to the east of the plant. It is recommended that addtional data be obtained when the plant is operating at its design capacity.

ii i 
Page

Introduction.

1

Noise Monitoring:

3

Data Collection and Analysis.

4

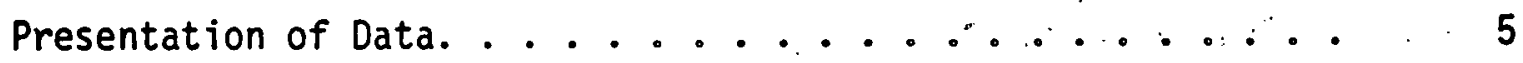

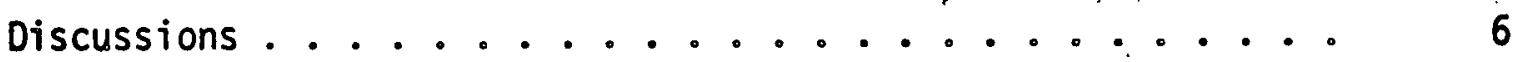

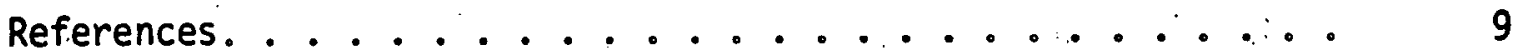

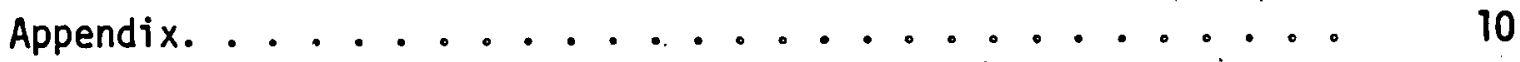

iv 
INTRODUCTION

The SYNTHANE Pilot Plant under consideration here is a pilot plant engineered and operated by the C-E Lummus Company for the U.S. Department of Energy. The plant utilizes the SYNTHANE (SYNthetic meTHANE) process developed by the Pittsburgh Energy Research Center of the Department of Energy and has a design capacity to convert 72 tons of coal per day into 1.2 million cubic feet of pipeline quality fuel gas.

The key steps of the process consist of:

Coal Preparation

Coal Pressurization

Gasification and Char Removal

Gas Cleanup

Shift Conversion

Acid Gas Removal

Methanation

Compression of Carbon Dioxide

Sulfur Removal

The concern here is strictly in regard to the noise emission from the plant rather than with respect to any of its operating characteristics. The principal noise producers in the plant can be divided into the following categories:

Mechanical: grinders, pulverizers, gears, conveyors

Flow Devices: fans, blowers, compressors, valves

Combustion: furnaces, flares, heaters

Electromechanical: generators, motors, transformers, circuit breakers 
Augmenting the operating noises are noises produced by maintenance operations and those resulting from truck movements.

The pilot plant is located in South Park Township, adjacent to the Bruceton Research Station of the U.S. Bureau of Mines which has been in the area for many years. A substantial portion of South Park Township is occupied by a county park which is its namesake. Aside from a number: of retail businesses in the area, the South Park Township is predominantly residential in nature. This area is general.ty very quiet as there are no major highways through the township. The closest highway in the vicinity is State Route 51 which runs through Jefferson Borough and is about $2 \frac{1}{2}$ miles east of the SYNTHANE plant. There are, however, three operating rail lines through the area namely, Pittsburgh and West Virginia, Baltimore and Ohio, and the Montour railroad.

The operation of the plant has drawn complaints. from its immediate neighbors concerning the noise emission from the plant, although, no attempt was made to substantiate these complaints with direct interviews with residents. From the author's discussion with plant engineers, it appears that complaints were mostly directed against the gas flare, the popping of the valves, the operation of the vacuum truck and, in general, noisy night-time operations. Some complaints came from as far as a mile away in an area east of the plant. This is probably due to the fact that the plant is situated in a valley which opens out to the east. Residents in other directions are probably somewhat protected by the ridge that partially surrounds the plant.

The immediate purpose of this study is to assess the magnitude of the noise impact upon the neighboring communities. This information can be used to formulate appropriate noise abatement measures or procedures. The long range objective is to gain some understanding of the noise problem that 
will be associated with commercial development of the SYNTHANE process.

\section{NOISE MONITORING}

In order to assess the noise impact on a given area, it is necessary to determine.(1) the noise level existing in the area prior to the introduction of the noise source under consideration into the area, and (2) the noise level when the source under consideration is in operation. The former noise level is referred to as the baseline level, while the latter, as the impacted level. Since, in the present case, baseline data is not available, and the plant cannot be' completely silenced to permit the collection of such data, an alternative approach must be employed. 1:The approach is to use "surrogate" sites'instead of the actual sites. To be acceptable, the'surrogate sites must have:an acoustical ambience comparable to that of the actual sites but are not impacted by the noise source under consideration. To this end, a total of eleven monitoring sites have been chosen in this study. These selected sites:are categorized as follows:

1. Sites 1 through 3 located along the boundary of the plant.

2. Sites 4 through 8 located at points'where complaints have originated from.

3. Sites 9 through 11 located in the general South Park area, but sufficiently far removed from any particular noisy operation or any major roadway.

A full description of the sites is given in Table 1.

Since it is to be expected that the noise at a given site will exhibit much temporal fluctuation, only continuous monitoring will portray the entire event. Such an extensive monitoring program is ruled out for the present study. Budgetary limitations required that only 8 hour samples be taken at the impacted sites, while 24 hour samples be taken to determine the baseline data. Actual monitoring is further limited to five minute samples for 
each sampling hour. To be useful, the sample data must yield acceptable estimates for the statistics of the noises under consideration. The statistics that are of the most interest here are the equivalent sound levels; $L_{\text {eq }}$, and specified percentile sound levels such as the $L_{10}$ and $L_{90}$ levels. For a given sampling scheme, the probable error is determined by the temporal characteristics of the noise. For relatively steady noises, such as those near the SYNTHANE plant, the error is expected to be smali, but for general environmental noises the error would be greater. This problem has not been adequately addressed to in the literature. Using five minute samples, the error, according to one study, (Ref. 1) can be as large as $4.5 \mathrm{~dB}$ for $L_{\text {eq }}$, $5 \mathrm{~dB}$ for $L_{10}$, and $2.5 \mathrm{~dB}$ for $L_{90}$ for noises, which are dominated by intermittent traffic and community activities. For the purpose of this study, these errors should be considered acceptable, as decisions involving environmental noises commonily have a resolution of only $5 \mathrm{~dB}$.

DATA COLLECTION AND ANALYSIS

Under the constraints of available instrumentation and with the intention of limiting field manpower and instrumentation requirements, the author opted for a two-step approach for acquiring the needed data. The first step is the field recording of the noise and the second step is the laboratory analys is of the recorded data. The link between the field and laboratory phases of the work is provided by the signal recorded at the beginning of each tape.

The field recording system consisted of a sound level meter, a battery powered tape recorder, and an acoustic signal generator for providing the necessary reference signal. A windscreen was used over the input microphone to eliminate wind generated noise. Recordings were not made whenever 
the wind speed exceeded 15 miles per hour. The frequency response of the sound level meter was set in the A-weighting mode as this practice will tend to reduce chances of either overloading the sound level meter, or saturating the magnetic tape. The sound level meter also served as a calibrated attenuator for the tape recorder. "On playback, the signal from the tape recording was fed through a calibrated attenuator into a level recorder. The signal coming out of the level recorder was then sorted by a distribution analyzer into various level intervals. A $5 \mathrm{~dB}$ interval was chosen for this study. The tape recorder has a dynamic range of about 45 decibel. The use of the intermediary attenuators during the recording, as well as the play back stage, greatly expanded the range of levels that can be handled by the system. As a matter of fact, by appropriately adjusting the input level at the start of a recording session, overloading was never observed. The period of measurement spanned the better parts of September and October. The days during which recordings were made are shown in Table 2 . The purpose of this tabulation is to enable any future correlation of the noise data with the plant operation $\log$ and other pertinent environmental data.

\section{PRESENTATION OF DATA}

The houriy sound level distributions are exhibited in Tables 3 through 13. From these data, the equivalent sound levels, $L_{d n}$ were computed and shown collectively in Table 14 . The $L_{d n}$ levels were obtained by averaging the daytime and night-time sound intensities over a 24-hour period with the night-time intensity augmented by a factor of 10. Details of the computation are included in the Appendix. For Sites 1 through 8 only, $L_{d}$ was measured and $L_{n}$ is assumed to equal $L_{d}$, since the plant operation noise is expected to stay essentially constant throughout an entire day. For sites 9 through 11 , the tabulated $L_{n}$ levels reflect the actual measured values. 
1. The baseline $L_{d n}$ levels were found to range from a low of 54 to a high of $59 \mathrm{dBA}$. The main source of noise is surface transportation, although small aircraft flyover noises were often: heard during the recording sessions. For the purpose of further discussion the baseline $L_{d n}$ level shall be taken to be $55 \mathrm{dBA}$ which is near the low end of the measured range.

2. The noise levels at Sites 4 through 8 are mostly higher than those found at farther away sites.' The only exception is the data obtained at Site 7'located on a farm off Gill Hall Road near a DOE monitoring station. Although at this site the plant was in full view, the noise from the plant was barely audible. The low level found at this site is due to the relatively greater distance from roadways. There is no question that traffic is an important component of the noise at Sites 6 and 8 , thus the $L_{d n}$ levels indicated at those sites tend to be an overestimation of the actual noise levels, as the traffic noise should die down considerably during the night-time hours!

3. The rather high level of noise at site 5 was found to be mostly due to a cinmercial sandblastingoperation on a nearby property. Assuming that the sandblasting activity will not continue into night-time hours the given $L_{d n}$ level at Site 5 is likely to be higher than the actual level." An evaluation of the measured noise levels in terms of existing state and federal regulations or recommendations (2) are shown in Table 15.

4. The impact on the surrounding neighborhood of the plant can be determined in either of two ways. One way is to use the measured $L_{d n}$ levels at the impacted sites. These levels ranged from 54 to $59 \mathrm{dBA}$ as explained in item 1, page 6 . The other method is to use the difference between the impacted level and the baseline level for the area. The former procedure was used by the Environmental Protection Agency (3) and the latter was adopted 
by the International Standards Organization (4). Using the procedure. defined by EPA, $5 \mathrm{~dB}$ should be added to the measured levels to account for the "suburban". nature of the area. For calculating the complaint impact according to the ISO procedure, a baseline level of $55 \mathrm{dBA}$. was chosen as a conservative value. (Refer to item 1 , page 6 ). The calculated Iso results: for Sites 4 through 8 are shown in Table 16. These calculations reveal.. that widespread complaints against the noise emitted from the pilot plant could come from an area as far as about a mile to the east of the plant.

5. The data reported thus far reflect really only the noise emitted by the plant in a "stand-by": mode, as throughout the project period the plant was not able to achieve sustained production operation as projected. Additional information should be collected when the design capacity is achieved, since the increase in the level of noise emission could be significant.

6. As a consequence of this study, a student research project was initiated and is currently in progress at the Graduate School of Public Health, the University of Pittsburgh. The intent of that project is to determine the realiability that can be ascribed to various sampling durations over a 24-hour period. The conclusion reached there will aid in the i.lterpretation of data reported herein. 
1. K. Eldred, Community Noise, EPA, NTID 300.3 (1971).

2. T. Yen, Noise Emission Considerations for Coal Conversion Processes. Report prepared for the Oak Ridge Associated Universitịes (1977).

3. Information on Levels of Environmental Noise Requisite to Protect Public Health and Welfare with an Adequate Margin of Safety, EPA 550/9 $74-004$ (1974).

4. Assessment of Noise with Respect to Community Response, International Organization for Standardization, 150/R 1966-1971. 
APPENDIX

The Calculation of Equivalent Sound Levels

To calculate $L_{d}$ or $L_{n}$ values from the data exhibited in Tables 3 through 13 , it is convenient to replace the integrals that are commonly used to define such levels with summations over discrete contributions from each designated level range. The appropriate formula is:

$$
L_{\text {eq }}=10 \log \frac{1}{100 n} \sum_{i=1}^{n}\left(10^{2} L_{i} / 10\right) P_{i}
$$

where $L_{i}$ is the center level in each level range. For example, 52.5 is taken at the center level in the range of 50 to $55 \mathrm{~dB}$ level range, etc. $P_{1}$ is the percent of time over the entire sampling period that the sound level fell within the corresponding level range, and $n$ is the total number of sampling hours in a given period.

Once the $L_{d}$ and $L_{n}$ levels are obtained for a given site, the resultant $L_{d n}$ level is given by the formula:

$$
L_{d n}=10 \log \frac{1}{24}\left((15) 10^{L_{d} / 10}+(9) 10^{\left.\left(L_{n}+10\right) / 10\right)}\right.
$$

9 
Table 1 - Description of monitoring sites.

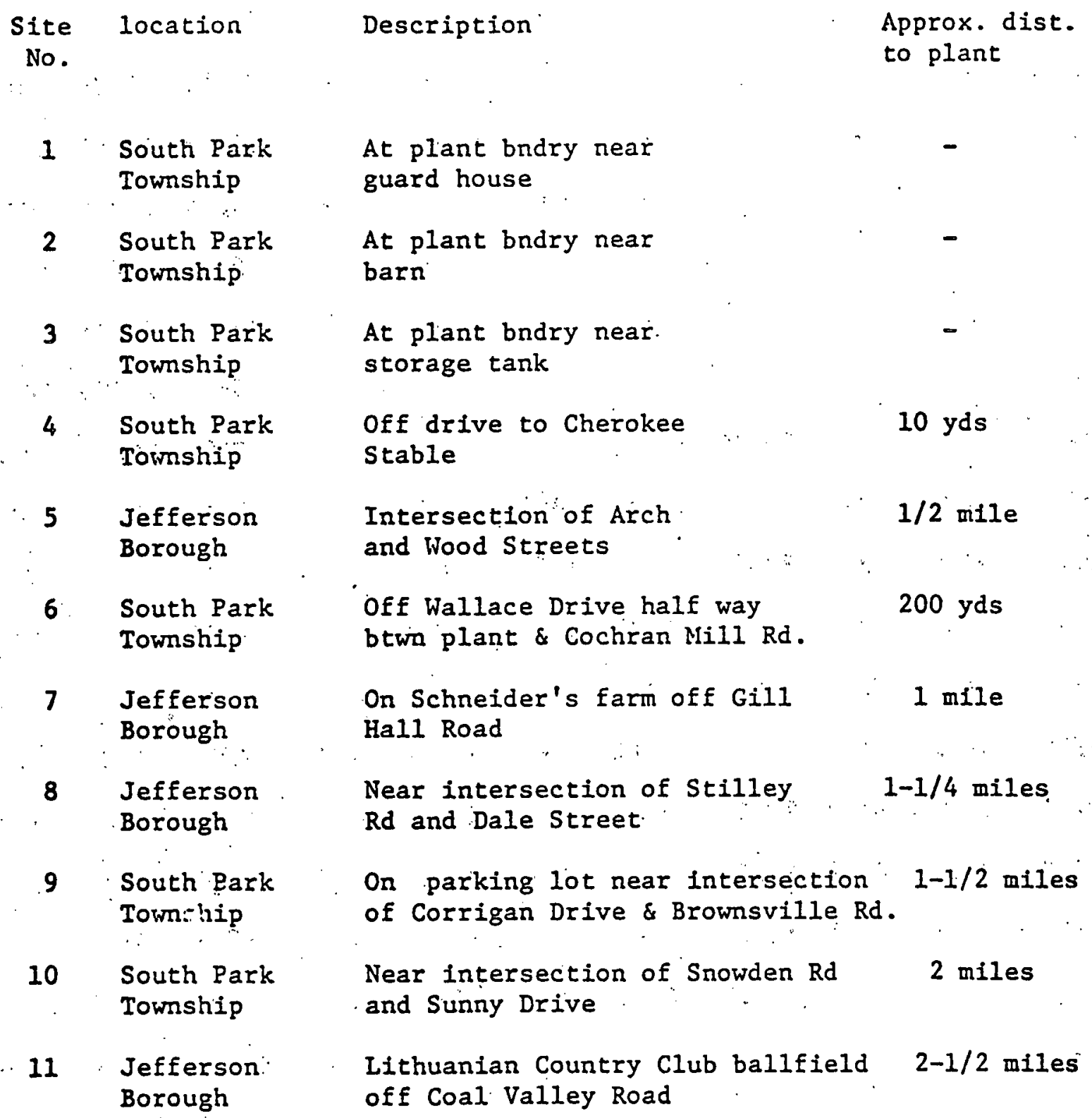


Table 2: Days on which data were obtained

Site designation

\begin{tabular}{|c|c|c|c|c|c|c|c|c|c|c|c|}
\hline Hour & 1 & 2 & 3 & 4 & 5 & 6 & 7 & 8 & 9 & 10 & 11 \\
\hline 0000 & & & & & & & & & & & \\
\hline 0100 & - & - & - & - & - & - & - & - & $10 / 1$. & $10 / 14$ & $10 / 10$ \\
\hline 0200 & - & - & - & - & - & - & - & - & $10 / 14$ & $10 / 14$ & $10 / 10$ \\
\hline 0300 & - & - & - & - & - & - & - & - & $10 / 14$ & $10 / 14$ & $.10 / 10$ \\
\hline 0400 & - & - & - & - & - & - & - & - & $10 / 14$ & $10 / 14$ & $10 / 10$ \\
\hline 0500 & - & - & - & - & - & - & - & - & $10 / 14$ & $10 / 14$ & $10 / 10$ \\
\hline 0600 & - & - & - & - & - & - & - & - & $10 / 26$ & $10 / 26$ & $: 10 / 21$ \\
\hline 0700 & - & - & - & - & - & - & - & - & $10 / 26$ & $10 / 26$ & $10 / 21$ \\
\hline 0800 & - & - & - & $10 / 26$ & - & - & - & - & $10 / 26$ & $10 / 26$ & $10 / 21$ \\
\hline
\end{tabular}

$\begin{array}{lllllllllll}9 / 14 & 9 / 14 & 9 / 14 & 10 / 11 & 10 / 11 & 10 / 26 & 10 / 11 & 10 / 11 & 9 / 21 & 9 / 21 & 9 / 21\end{array}$ 0900

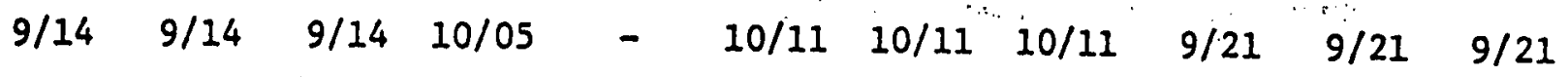
1000

$\begin{array}{lllllllllll}9 / 14 & 9 / 14 & 9 / 14 & 10 / 05 & 10 / 11 & 10 / 11 & 10 / 11 & 9 / 21 & 9 / 21 & 9 / 21\end{array}$ 1100 $\begin{array}{lllllllllllll}9 / 14 & 9 / 14 & 9 / 14 & - & 10 / 11 & - & 10 / 11 & 10 / 11 & 9 / 21 & 9 / 21 & 9 / 21\end{array}$ 1200 $\begin{array}{llllllllllll}9 / 19 & 9 / 19 & 9 / 19 & -10 / 11 & 10 / 11 & 9 / 23 & 9 / 21 & 9 / 21\end{array}$ 1300

$\begin{array}{llllllllllllllll}9 / 19 & 9 / 19 & 9 / 19 & 10 / 05 & 10 / 05 & 10 / 11 & 10 / 11 & 10 / 11 & 9 / 20 & 9 / 20 & 9 / 20\end{array}$ 1400 $\begin{array}{lllllllllll}9 / 19 & 9 / 13 & 9 / 19 & 10 / 05 & 10 / 05 & 10 / 11 & 10 / 11 \cdots 10 / 11 & 9 / 20 & 9 / 23 & 9 / 23\end{array}$ 1500 $\begin{array}{llllllllllll}9 / 19 & 9 / 19 & 9 / 19 & 10 / 05 & 10 / 05 & 10 / 06 & 10 / 06 & 10 / 06 & 9 / 23 & 9 / 23 & 10 / 07\end{array}$ 1600 - 10/05 10/05 10/06 10/06 10/06 9/23 9/23 10/07 1700 1800 1900 2000 2100 2200 2300 2400 
Table 3: Sample hourly sound level distribution for Site No. 1 Sound level, dBA

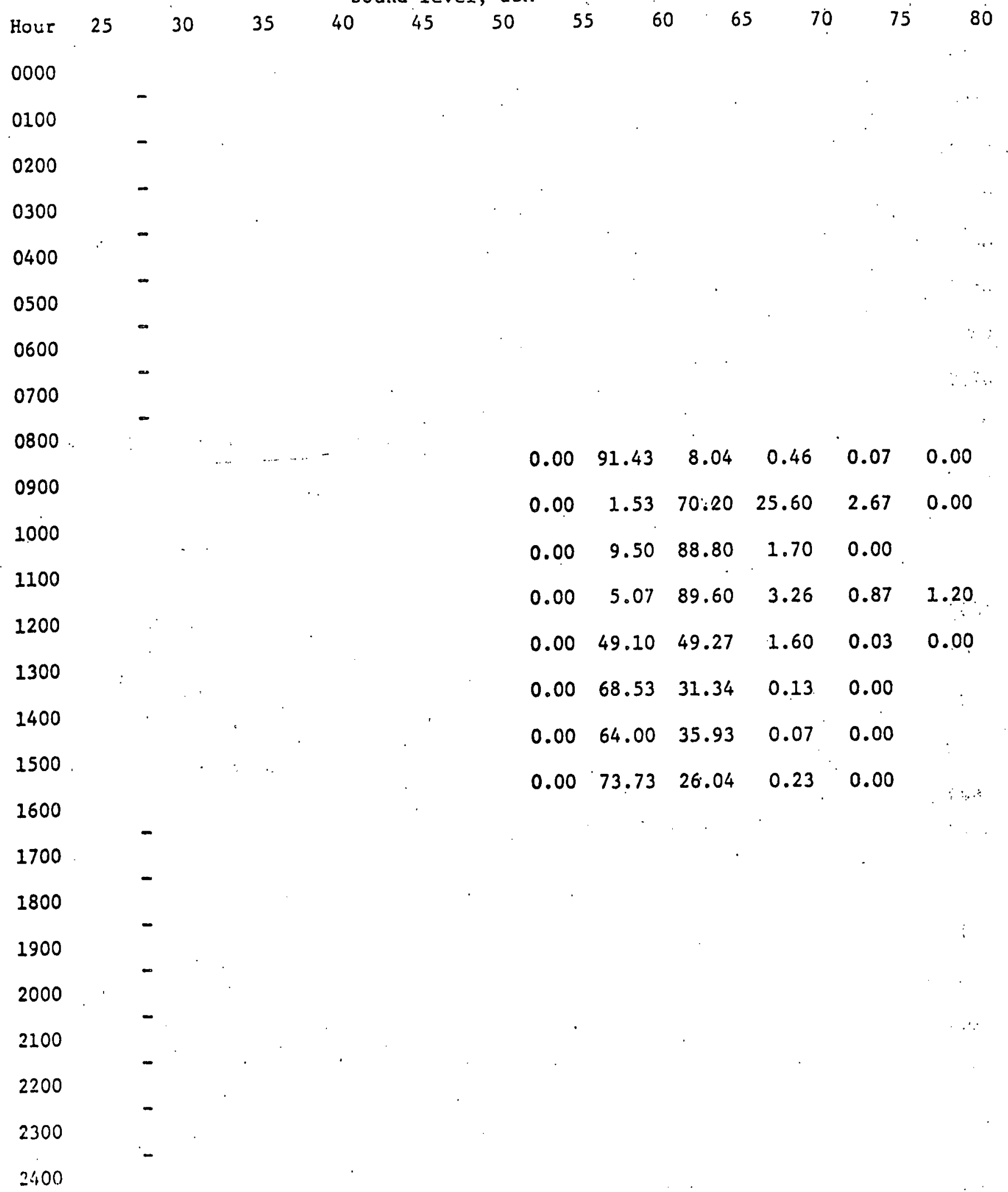


Table 4: Saiple hourly sound level distribution for site No. 2

Sound level, dBA

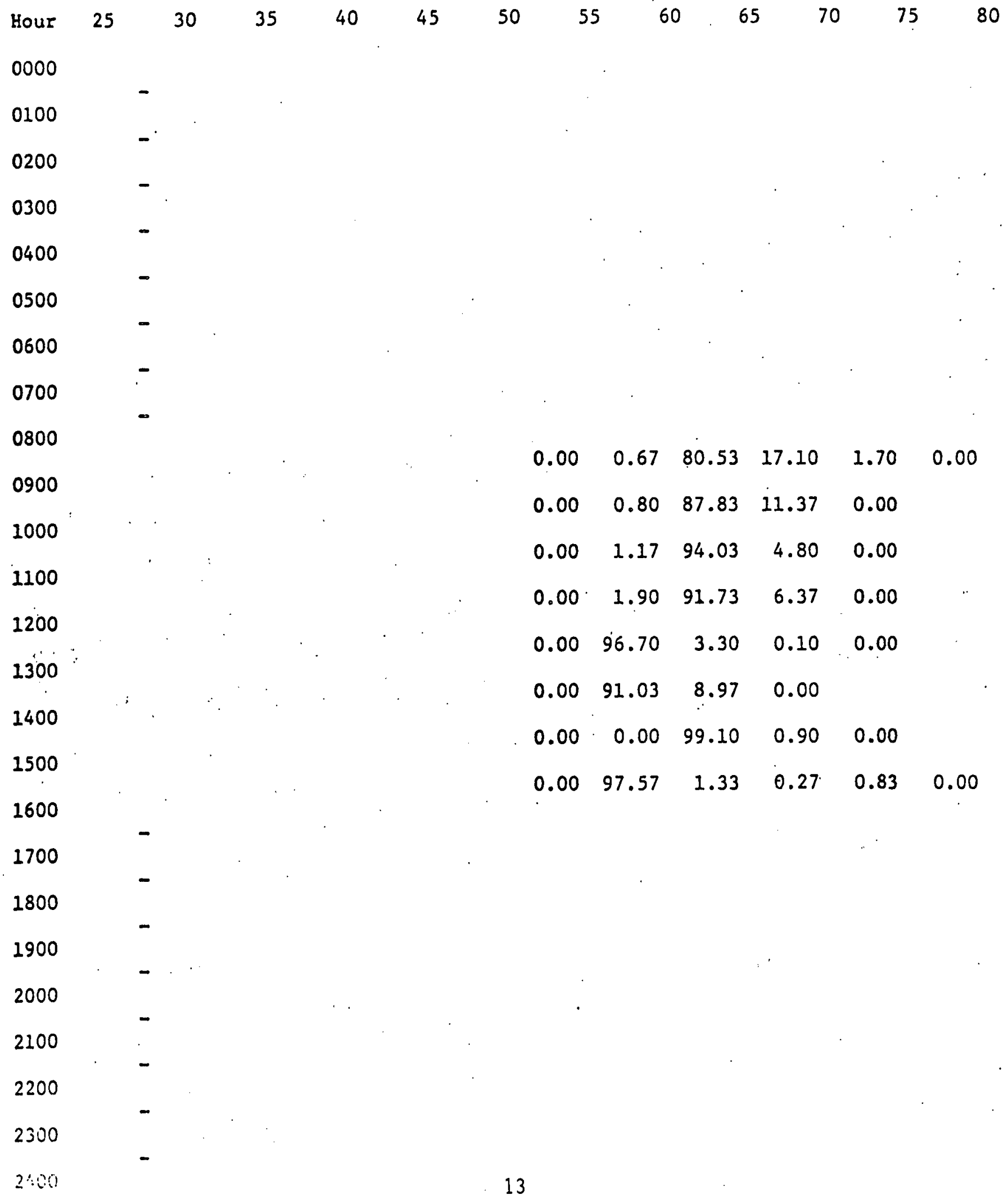


Table 5: Sample hourly sound level distribution

for site ko. 3 .

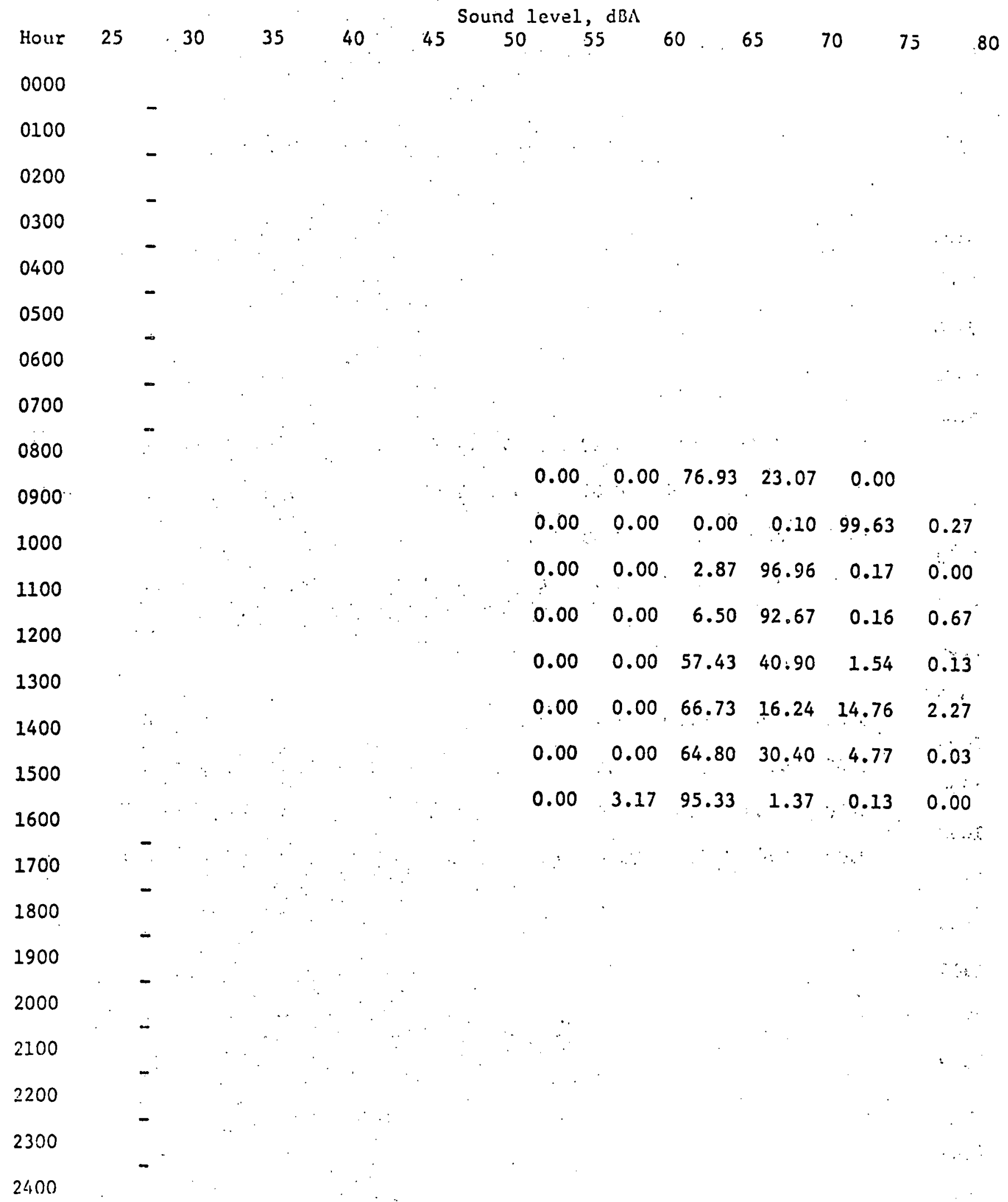


Table 6: "Sample hourly, sound level distribution

for Site-No. 4

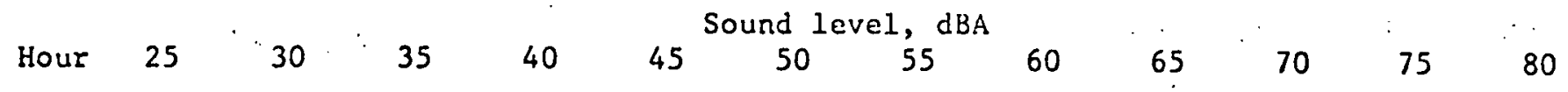

$$
\begin{aligned}
& 0000 \\
& 0100 \\
& 0200 \\
& 0300 \\
& 0400 \\
& 0500 \\
& 0600 \\
& 0700 \\
& 0800 \\
& 0900 \\
& \therefore \\
& \begin{array}{lllll}
0.00 & 0.00 & 0.00 & 0.00 & 77.03
\end{array} \\
& 3.07 \quad 74.73 \quad 18.43 \\
& 2.44 \quad 1.03 \\
& 0.30 \\
& 0.00 \\
& 0.00 \\
& 0.00 \\
& 0.00 \cdots 0.00 \quad 0.00 \quad 54.27 \\
& 16.80 \\
& 3.94 \\
& 2.06 \\
& 0.17 \\
& 0.00 \\
& 0.00 \\
& 1000 \\
& 1100 \\
& 0.00 \\
& 0.00 \\
& 0.00 \\
& 3.4758 .33 \\
& 38.70 \\
& 3.06 \quad 1.54 \quad 1.13 \\
& 1.30 \\
& 0.00 \\
& \begin{array}{lllllllllllll}
0.00 & 0.00 & 0.00 & 5.47 & 42.76 & 33.94 & 11.26 & 4.74 & 1.36 & 0.47 & 0.00
\end{array} \\
& \begin{array}{lllllllllll}
0.00 & 0.00 & 0.00 & 37.03 & 18.64 & 3.93 & 11.47 & 8.13 & 6.93 & 9.4 \div & 4.43
\end{array}
\end{aligned}
$$

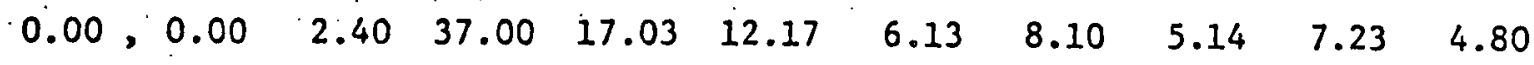

$$
\begin{aligned}
& \begin{array}{lllllllllll}
0.00 & 0.00 & 0.00 & 19.63 & 44.64 & 12.80 & 8.36 & 4.97 & 3.80 & 4.63 & 1.17
\end{array}
\end{aligned}
$$

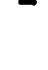


Table 7: Sample hourly sound level. distribution

for Site No. 5

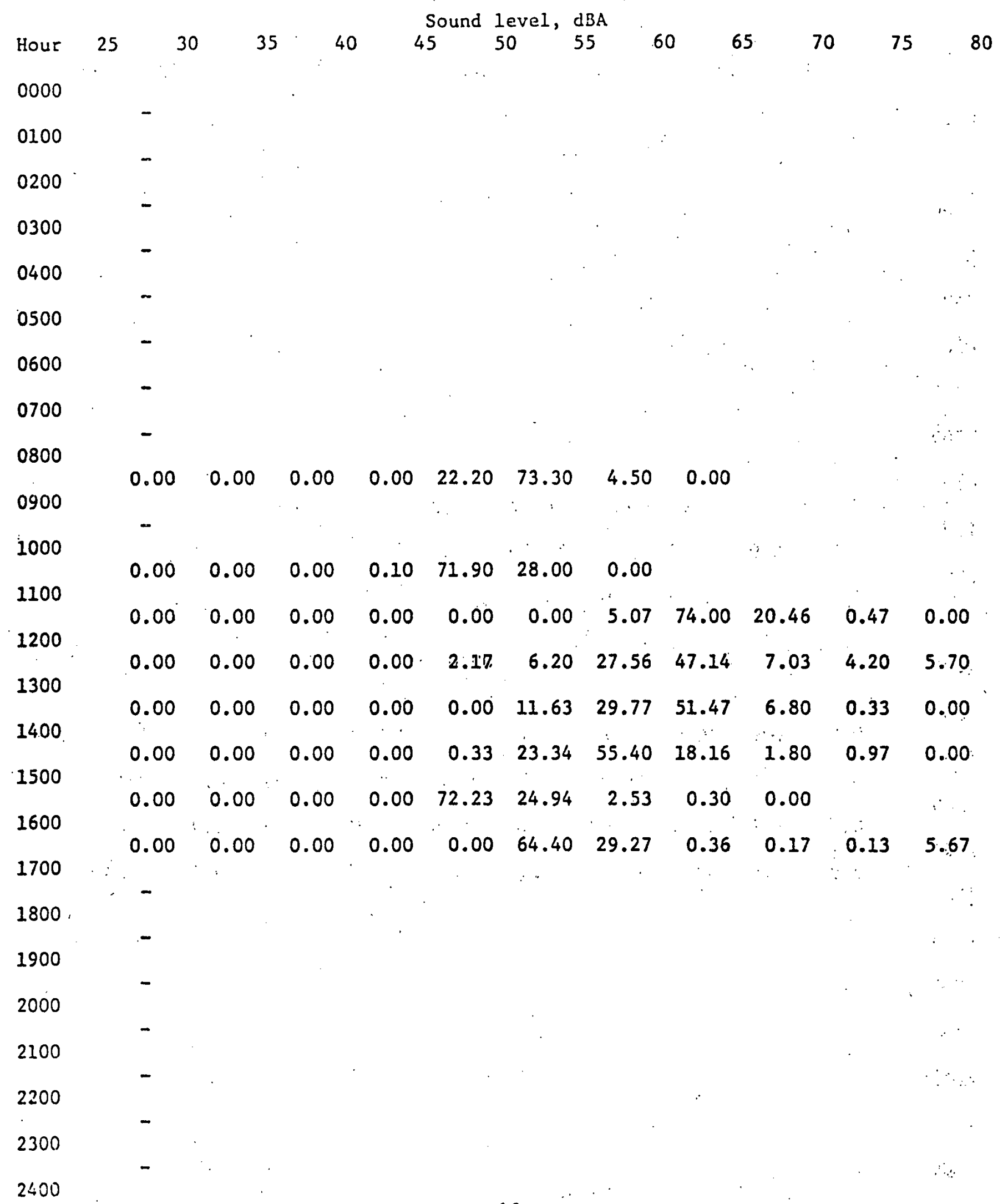


Table 8: Sample hourly saund level distribution for Site $\therefore .6$

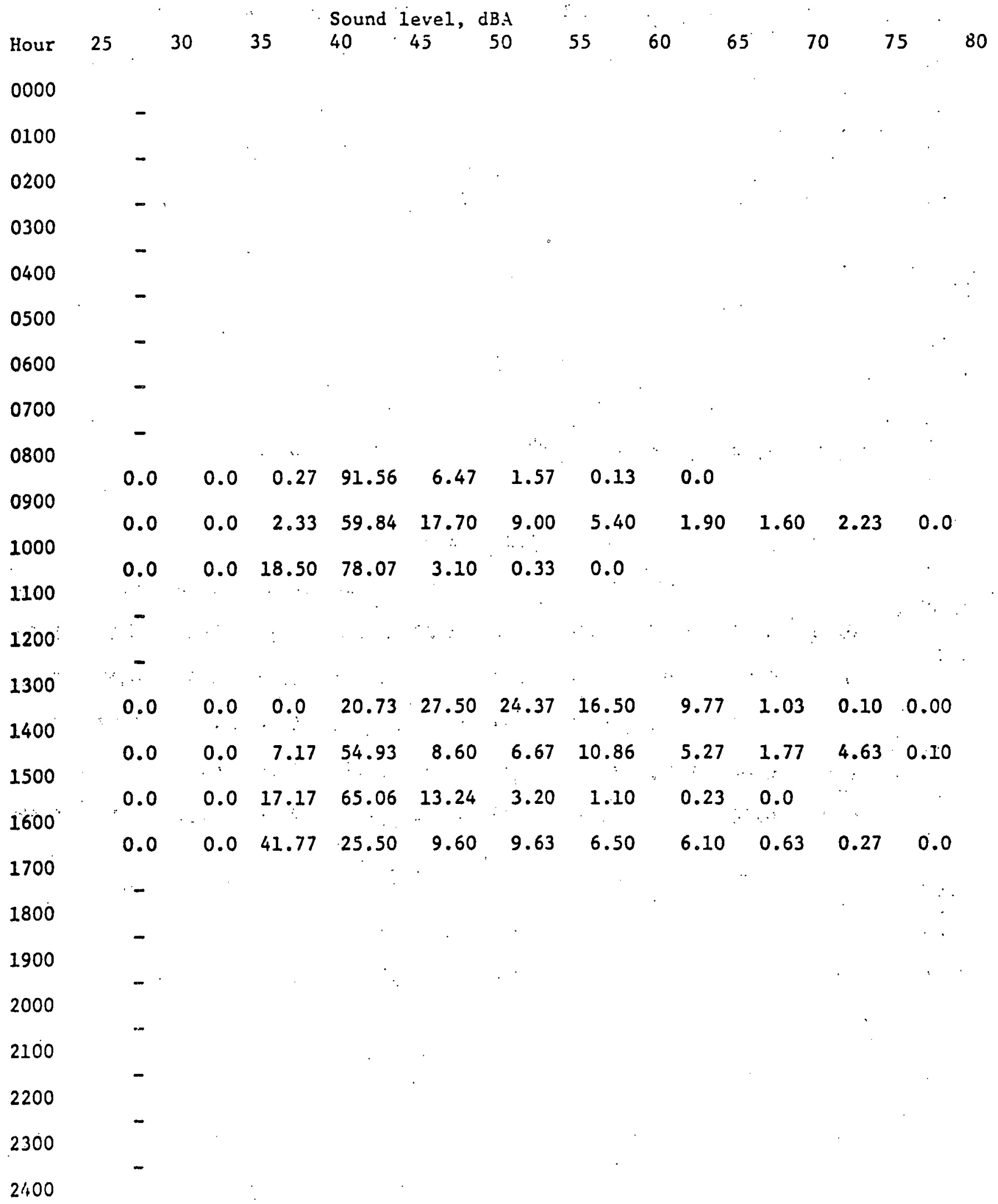


Tabie 9: Sample hourly sound level distribution

for site $\because n .7$

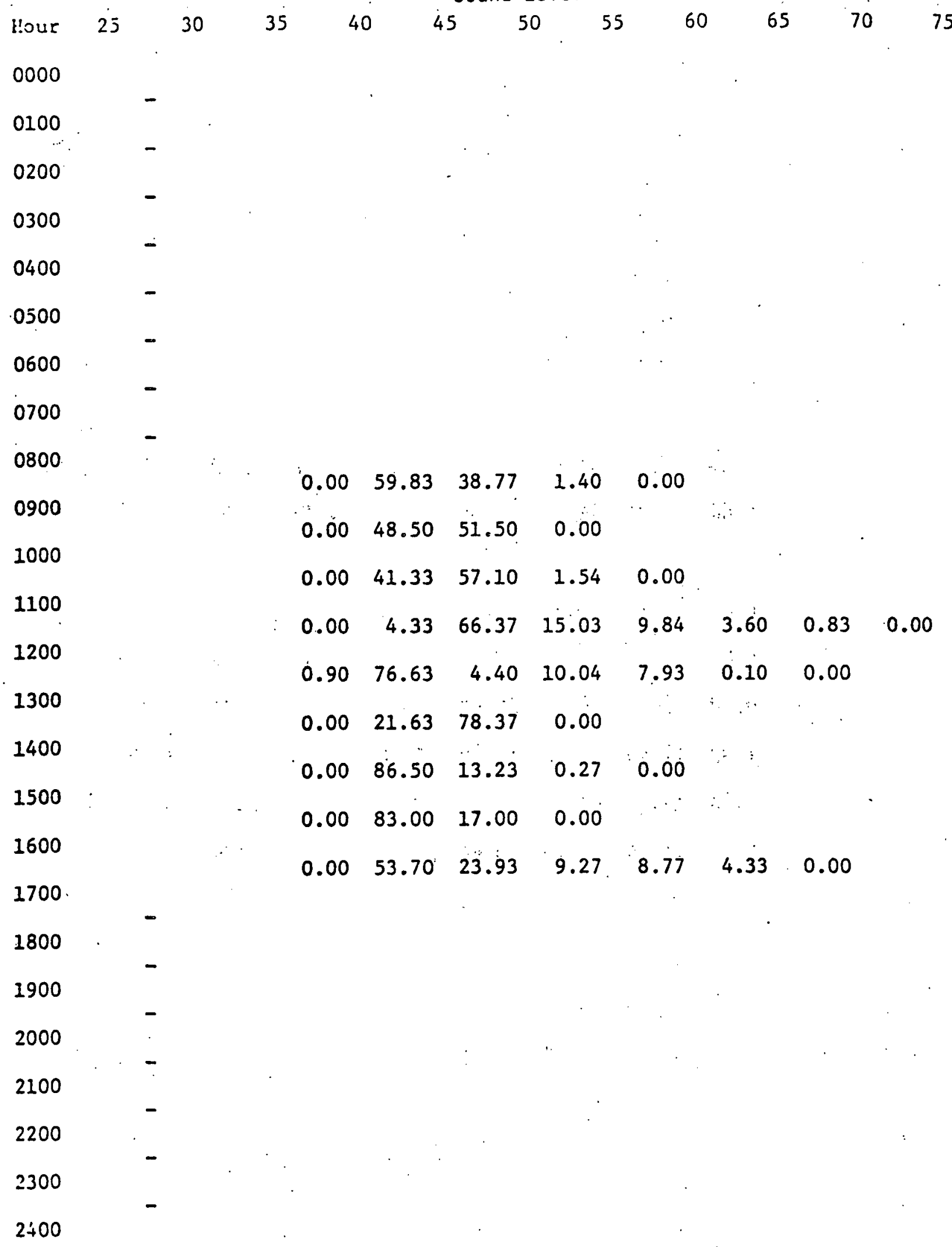


Table 10: Sanple hourl: sound level distribution for site :in. 8

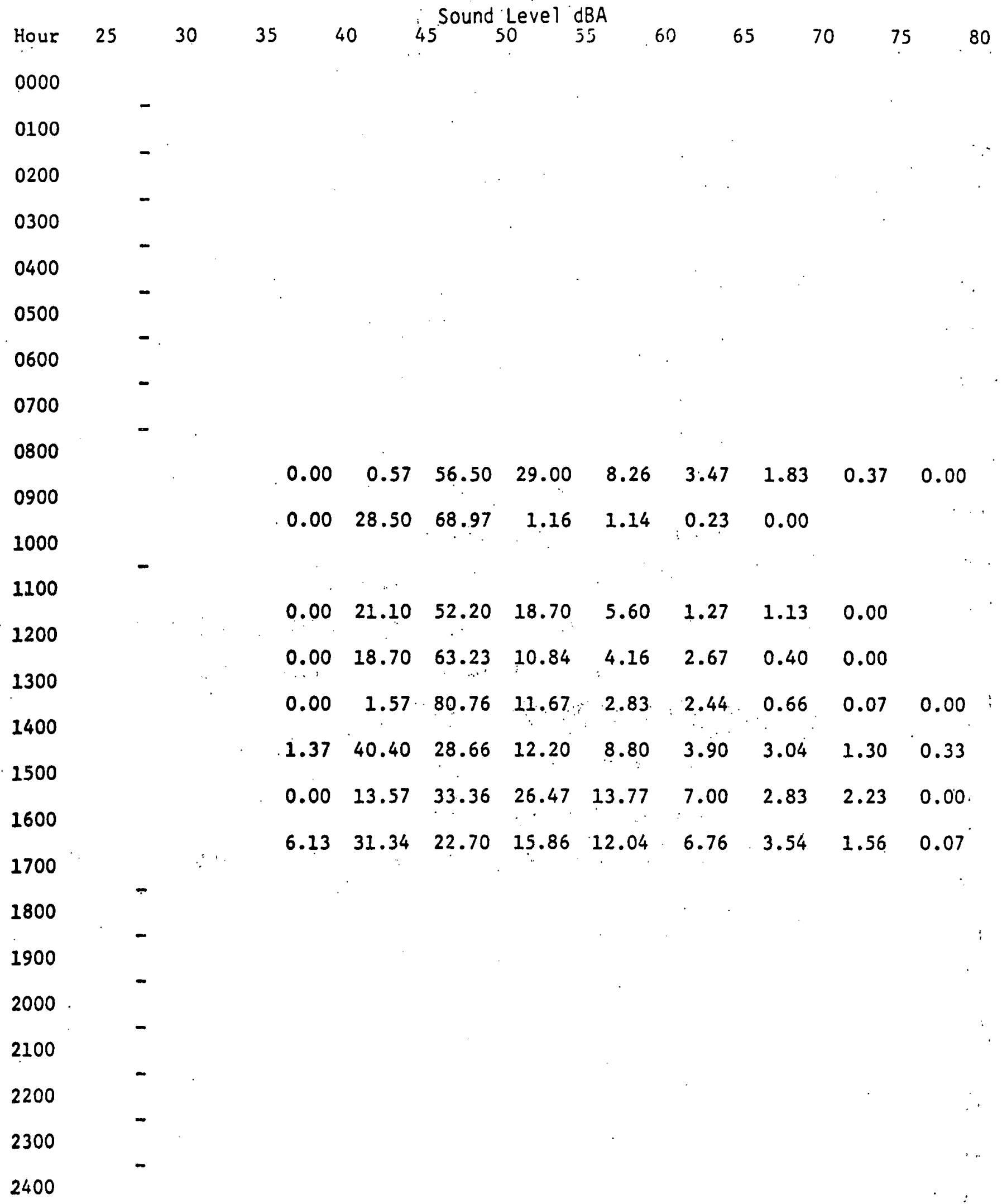


Table 11: Sample hourly sound level distribution for site No. 9

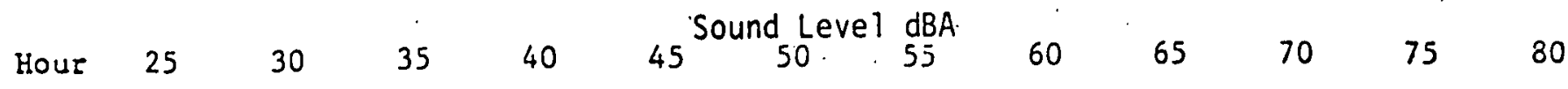

0000

0100

$\begin{array}{llllllll}0.00 & 6.27 & 28.26 & 31.00 & 23.14 & 10.83 & 0.50 & 0.00\end{array}$

0200

$\begin{array}{lllllll}1.23 & 64.80 & 23.20 & 6.14 & 4.40 & 0.23 & 0.00\end{array}$

$\begin{array}{llllllll}0.07 & 80.86 & 7.47 & 6.37 & 2.90 & 2.13 & 0.17 & 0.00\end{array}$

0300

$\begin{array}{lllllll}18.10 & 73.27 & 4.83 & 1.33 & 1.27 & 1.20 & 0.00\end{array}$

0400

$\begin{array}{lllllll}0.63 & 84.57 & 11.33 & 1.74 & 0.73 & 0.90 & 0.00\end{array}$

0500

0600

$\begin{array}{llllllll}0.00 & 0.00 & 61.17 & 23.90 & 8.60 & 3.73 & 2.40 & 0.20\end{array}$

0700

$\begin{array}{lllllll}0.00 & 59.33 & 26.27 & 6.47 & 6.06 & 1.87 & 0.00\end{array}$

0800

0900

1000

$\begin{array}{lllllll}0.00 & 19.80 & 20.70 & 31.17 & 20.66 & 6.84 & 0.00\end{array}$

$\begin{array}{llllllll}0.00 & 13.67 & 30.53 & 39.00 & 12.63 & 3.47 & 0.70 & 0.00\end{array}$

$\begin{array}{llllllll}0.00 & 0.47 & 34.20 & 42.83 & 19.07 & 2.20 & 1.23 & 0.00\end{array}$

1100

$\begin{array}{lllllllll}0.00 & 2.13 & 31.44 & 25.53 & 18.10 & 13.90 & 7.40 & 1.50 & 0.00\end{array}$

$\begin{array}{lllllllll}0.00 & 11.63 & 34.44 & 31.30 & 14.60 & 3.56 & 3.07 & 1: 40 & 0.00\end{array}$

1200

$\begin{array}{lllllllll}0.00 & 1.30 & 24.50 & 44.33 & 20.24 & 3.23 & 4.73 & 1.67 & 0.00\end{array}$

1300

$\begin{array}{llllllllll}0.00 & 0.00 & 1.67 & 20.80 & 4.00 & 16.36 & 37.40 & 19.20 & 0.57 & 0.00\end{array}$

1.400

1500

1600

1700

1800

1900

$\begin{array}{llllllllll}0.00 & 22.93 & 49.97 & 18.47 & 4.14 & 2.00 & 1.06 & 1.54 & 0.03\end{array}$

$\begin{array}{lllllllll}0.00 & 6.73 & 35.24 & 35.00 & 12.20 & 6.30 & 4.40 & 0.13 & 0.00\end{array}$

$\begin{array}{llllllll}0.00 & 10.87 & 35.83 & 36.40 & 13.33 & 3.07 & 0.50 & 0.00\end{array}$

$\begin{array}{lllllllll}0.00 & 8.63 & 31.40 & 28.80 & 17.40 & 9.40 & 4.34 & 0.03 & 0.00\end{array}$

$\begin{array}{lllllllll}0.00 & 8.97 & 31.76 & 35.04 & 11.83 & 3.00 & 3.17 & 6.23 & 0.00\end{array}$

$\begin{array}{llllll}0.00 & 14.10 & 24.10 & 28.07 & 6.87 & 0.00\end{array}$

2000

2100

$\begin{array}{llllllllll}0.00 & 0.30 & 10.40 & 19.20 & 30.27 & 25.60 & 9.50 & 3.50 & 1.16 & 0.07\end{array}$

$\begin{array}{lllllll}0.00 & 1.1 .57 & 25.30 & 23.23 & 10.37 & 6.10 & 0.00\end{array}$

2200

2300

$\begin{array}{lllllllll}0.00 & 0.43 & 29.30 & 28.00 & 21.84 & 17.26 & 2.67 & 0.50 & 0.00\end{array}$

2400

$\begin{array}{lllllllll}0.00 & 30.50 & 23.43 & 9.40 & 21.14 & 12.33 & 2.50 & 0.70 & 0.00\end{array}$ 
Table 12: Sample hourly sound level distribution

for Site: No. 10

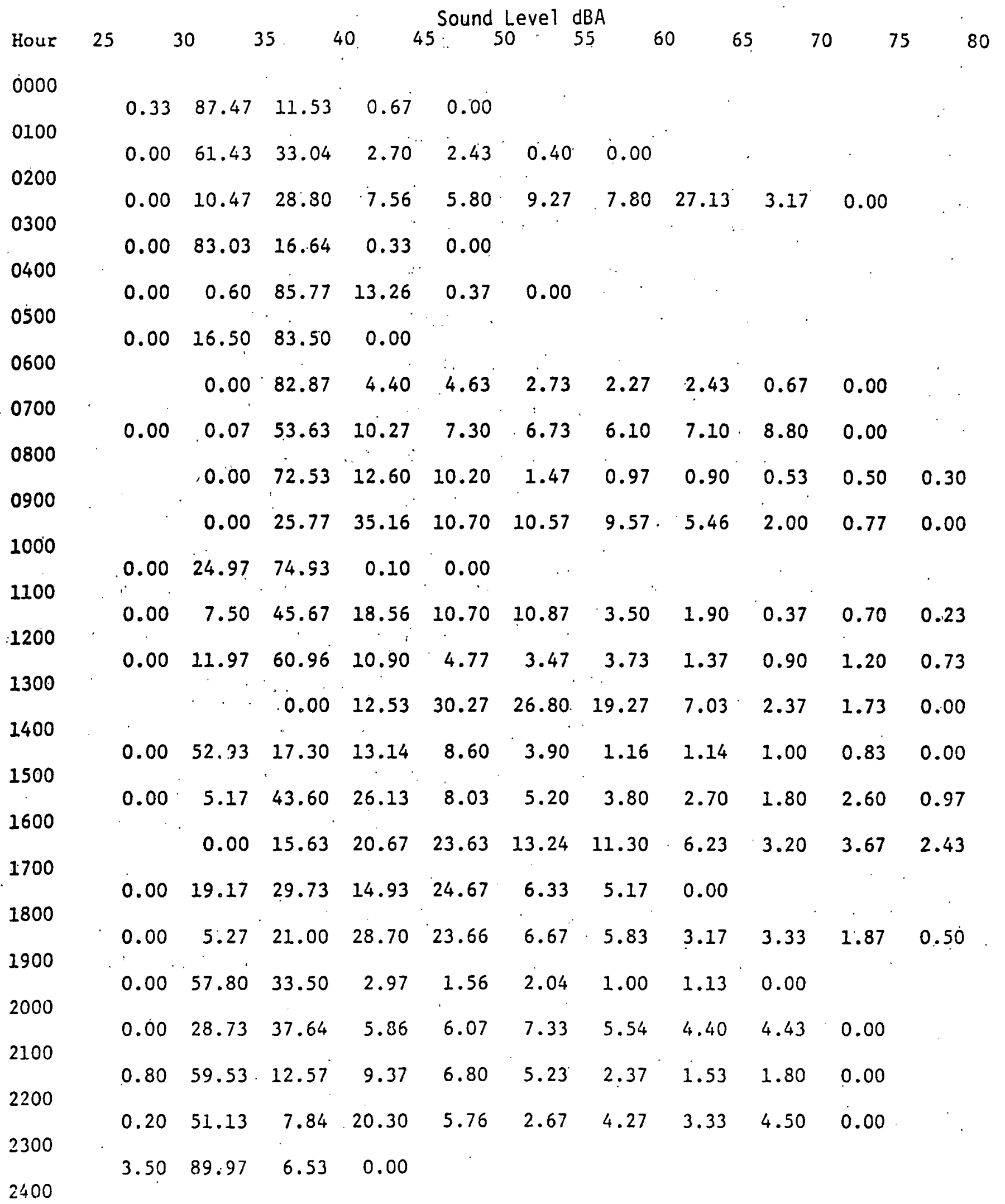


Table 13: Sunple hourly solind l.ẹvel distribution for site 110.11 .

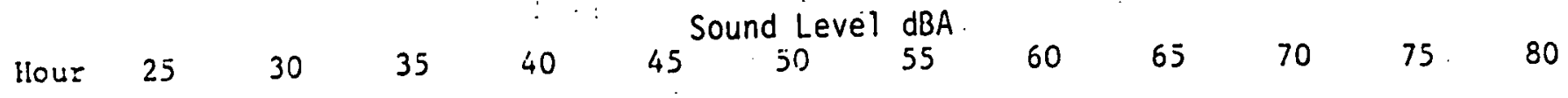

0000

0100

$\begin{array}{lllll}0.00 & 19.70 & 79.50 & 0.80 & 0.00\end{array}$

0200

$0.00 \quad 1.50 \quad 75.50 \quad 15.80$

$5.90 \quad 1.30 \quad 0.00$

0300

$\begin{array}{llllll}0.00 & 1.30 & 78.00 & 18.30 & 2.40 & 0.00\end{array}$

0400

$\begin{array}{lllll}0.00 & 8.30 & 85.20 & 6.50 & 0.00\end{array}$

$\begin{array}{llllll}0.00 & 0.10 & 66.10 & 17.70 & 12.40 & 3.70\end{array}$

0500

$\begin{array}{lllll}18.70 & 77.80 & 3.40 & 0.10 & 0.00\end{array}$

0600

$\begin{array}{lllllll}0.70 & 40.00 & 43.70 & 12.90 & 1.70 & 1.00 & 0.00\end{array}$

0700

0800

$\begin{array}{lllllll}3.40 & 35.60 & 51.00 & 8.80 & 1.10 & 0.10 & 0.00\end{array}$

$\begin{array}{lllllllll}0.00 & 0.10 & 26.70 & 41.50 & 18.10 & 9.70 & 3.80 & 0.10 & 0.00\end{array}$

0900

$0.00 \quad 47.13 \quad 32.20 \quad 10.94$

$5.60 \quad 2.16 \quad 1.54$

$0.43 \quad 0.00$

1000

0.00

$\begin{array}{lllllll}4.40 & 59.40 & 16.80 & 11.17 & 7.66 & 0.57 & 0.00\end{array}$

1100

$\begin{array}{llllllll}0.00 & 40.90 & 45.17 & 9.16 & 3.54 & 1.10 & 0.13 & 0.00\end{array}$

1200

$\begin{array}{lllllll}0.00 & 31.83 & 41.80 & 12.57 & 11.87 & 1.93 & 0.00\end{array}$

1300

$\begin{array}{llllllll}0.00 & 0.23 & 46.04 & 37.13 & 15.03 & 1.57 & 0.00\end{array}$

1400

1500

0.00

$\begin{array}{llllllll}0.87 & 64.26 & 22.60 & 8.17 & 3.03 & 1.05 & 0.02 & 0.00\end{array}$

1600

$\begin{array}{llllllllllll}0.00 & 38.80 & 25.20 & 24.33 & 8.34 & 2.20 & 1.13 & 0.00\end{array}$

1700

$\begin{array}{lllllll}0.00 & 42.33 & 30.67 & 20.43 & 6.34 & 0.23 & 0.00\end{array}$

1800

$\begin{array}{lllllll}0.00 & 23.60 & 45.70 & 21.60 & 8.40 & 0.70 & 0.00\end{array}$

1900

$\begin{array}{llllllll}0.00 & 13.00 & 43.40 & 26.20 & 12.30 & 3.40 & 1.70 & 0.00\end{array}$

2000

$\begin{array}{lllllll}0.00 & 4.20 & 65.40 & 20.00 & 9.00 & 1.40 & 0.00\end{array}$

2100

2200

2300

$\begin{array}{llllll}0.00 & 50.20 & 39.40 & 7.40 & 3.00 & 0.00\end{array}$

$\begin{array}{lllllll}0.00 & 51.50 & 38.70 & 8.40 & 1.20 & 0.20 & 0.00\end{array}$

$\begin{array}{lllllllll}0.00 & 0.80 & 72.80 & 22.30 & 2.40 & 0.80 & 0.70 & 0.20 & 0.00\end{array}$

$0.00 \quad 66.30 \quad 26.70 \quad 5.60 \quad 1.40 \quad 0.00$

2400 
Table 14: Day and night equivalent sound levels at. the monitoring sites

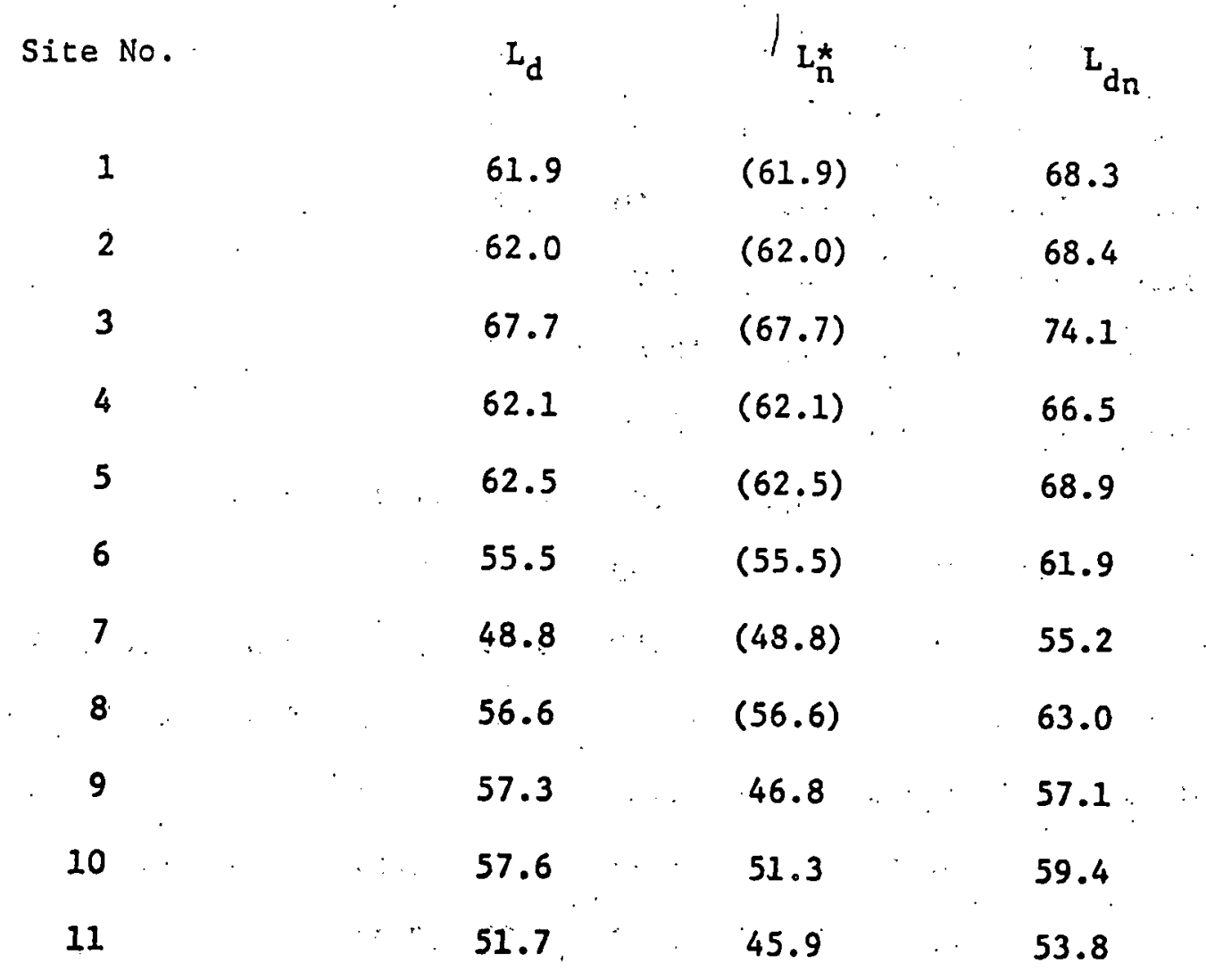

* Note: Numbers in parentheses are assumed to be identical to the respective
day-time levels. 
Table 15: Rating the measured noise levels according to existing regulations or recomendations for residential uses

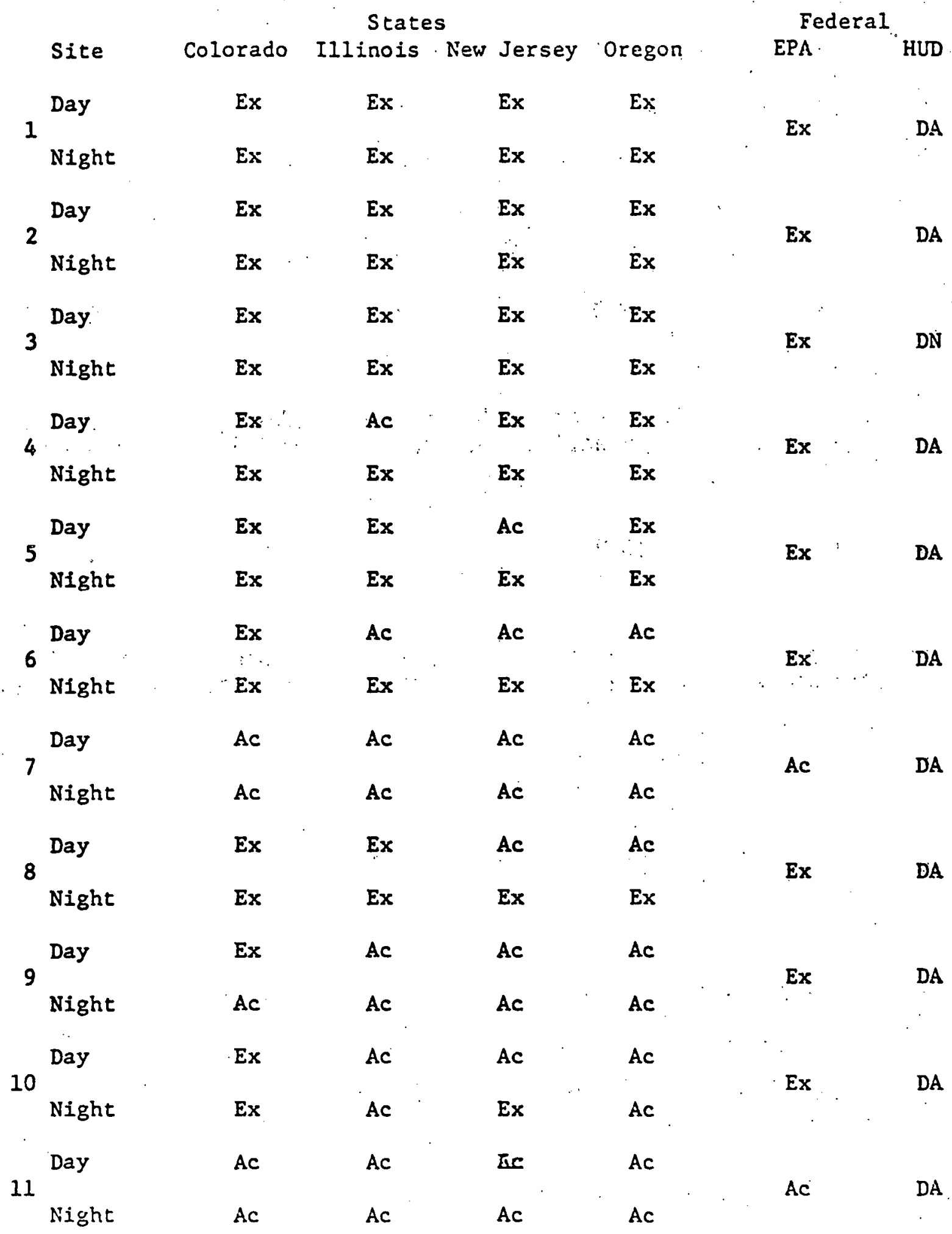

Legend: $\Lambda c=$ Acceptable

$\mathrm{Ex}=$ Excessive

DA = Discretionary - normally Acceptable

DN = Discretionary - nornally Unacceptasle 
Table 16: Characterizing the impact at Sites 4 through 8

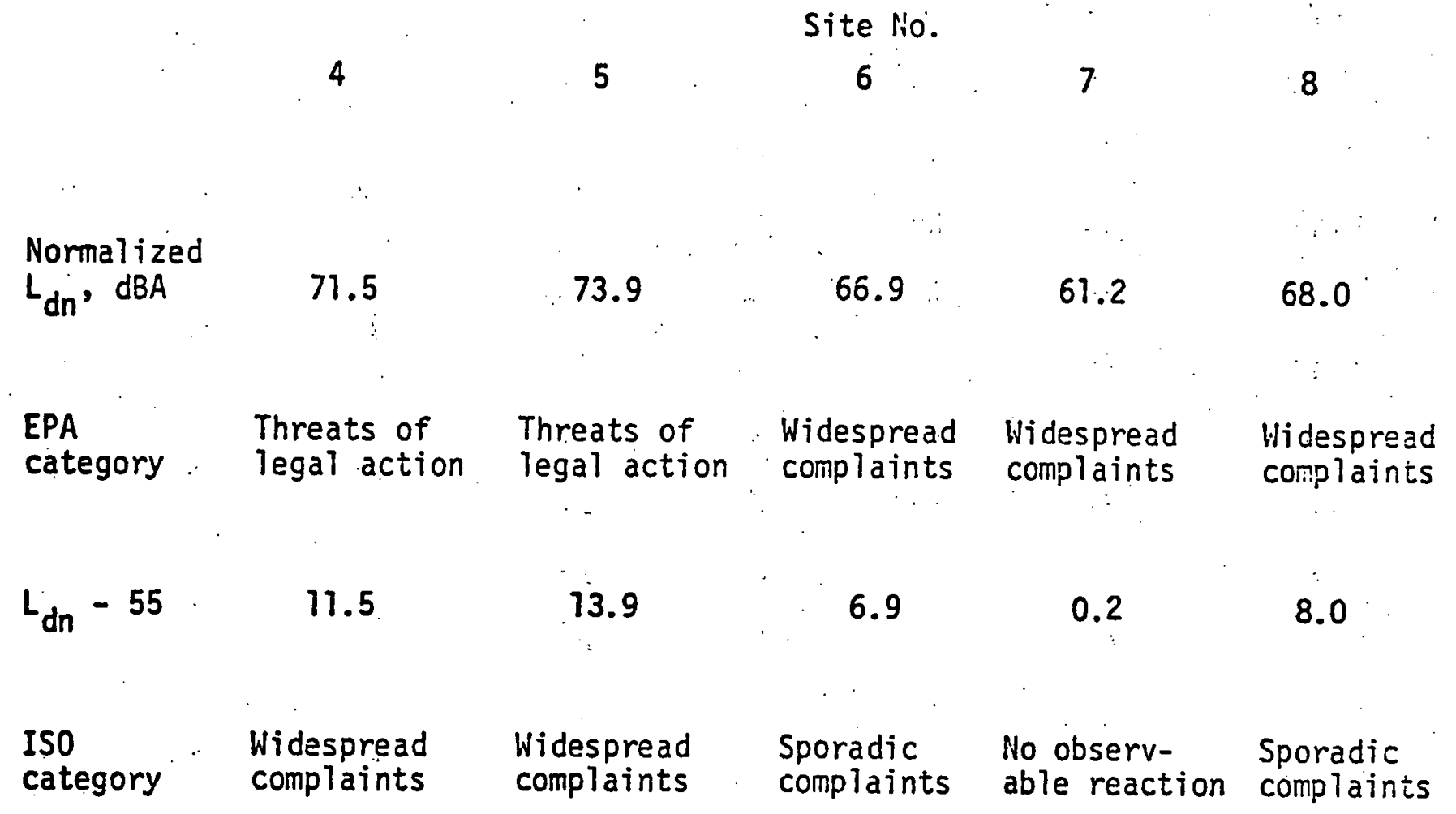

\U.S. GOVERNMENT PRINTINC OFFICF. 1979.640.092. 1108 